\title{
Investigation on the Compressive Strength of Gunny Sack Fiber Concrete under High-Temperatures
}

\author{
Nur Fithriani F. Cholida ${ }^{*}$, Purwanto $^{1}$, and Hani Purwanti ${ }^{1}$ \\ ${ }^{1}$ Department of Civil Engineering, Universitas Semarang, Indonesia \\ *Corresponding author: tiafithria@gmail.com
}

(Received: January $15^{\text {th }}, 2020$; Revised: March 21 $1^{\text {st }}, 2020$; Accepted: March $23^{\text {rd }}, 2020$ )

\begin{abstract}
Gunny sack fiber concrete has not been explored especially the behavior under high temperatures. This paper presents the results of an experimental investigation of gunny sack fibrous concrete (percentage of $0.5 \%$ of volume) given a monotonic- compressive load. A number of cylindrical test specimens were made which consisted of control specimens and which were incinerated at temperatures of $300^{\circ} \mathrm{C}, 600^{\circ} \mathrm{C}$ and $900^{\circ} \mathrm{C}$. The concrete -compressive strength was designed with three variations of the cement water ratio to get the compressive strength of a standard cylinder with normal, medium and high quality compressive strength categories. Experimental results show that normal to high quality concrete can be produced with gunny sack fiber substitution. The compressive strength of the gunny sack fiber concrete decreased significantly from the control specimen to the specimen which was burned at $300^{\circ} \mathrm{C}$. The loss of compressive strength from the control specimens to the post-burn specimens of medium quality and high -quality of gunny sack fiber concrete was the same compared with the loss of compressive strength of normal- quality concrete. This study also carried out a comparison of the degradation of the compressive strength of steel fibrous concrete with gunny sack fiber in post-burn conditions.
\end{abstract}

Keywords: fiber; gunny sack fiber; compressive strength; temperatures

\section{Introduction}

Concrete is a building material that has superior fire/heat resistance compared to other types of material, such as wood or steel. It is because concrete is a low conductor of heat (low thermal conductivity), for that reason it can limit the depth of heat penetration. In addition to these advantages, concrete is also relatively easy to repair. Thus there is a need for forensic engineering to find out and investigate the mechanism causing a structural failure. Several studies about the thermal properties of concrete materials to high temperatures have been extensively investigated [1-3]. On the contrary, the main purpose of using concrete covers (reinforced concrete) in reinforced concrete structures is to protect the reinforcement from infiltration of chloride ions in order to avoid the occurance of corrosion, and the second one is to decline the heat entering the reinforcement in case of fire. The propagation of heat from the concrete surface into the reinforcement is determined both by the thickness of the blanket and the quality of the concrete. Because of the properties of the burnt concrete, including the duration and the temperature of the fire are very important to recognize in order to ensure the level of security of after burnt structure.

Recently, fibrous concrete, especially steel fibrous, has been a popular alternative material choice due to its excellent mechanical properties, adhesion, and ductility compared with normal concrete (without fiber) [4-8]. The mechanical properties of steel fiber concrete at high temperatures have 
also been extensively investigated [9-12]. Similarly, the application of fibrous concrete at high temperatures has been carried out [13].

Gunny or Rami in Indonesian language, is a vegetable fiber plant exclude cotton. This gunny fiber is brown and lighter. This plant grows in the tropical and sub-tropical area, the Equator. Gunny fiber has excellent quality and tensile strength [14]. Antonius's results revealed that gunny -fibrous concrete has very good potential as a concrete material with good mechanical properties, including higher ductility rather than ductility of normal concrete. Nevertheless, the behavior of the gunny-fibrous concrete is not specifically known when it is at high temperatures. Hence, it needs further research concerning its mechanical properties when at high temperatures.

This research was conducted with the main objective to evaluate their behavior at normal to high temperatures. The percentage of gunny fiber is set at $0.5 \%$ of the volume of concrete. The parameters reviewed included concrete compressive strength (normal, medium and highcompressive strength), and temperature variations (normal as control, $300^{\circ} \mathrm{C}, 600^{\circ} \mathrm{C}$ and $900^{\circ} \mathrm{C}$ ), but this research is limited to the discussion of concrete compressive strength.

\section{Experimental Procedures}

\subsection{Material}

Gunny fibers used is shown in Fig. 1. Material properties such as water absorption, density, tensile strength etc have been explained by Antonius et al. [14]. Concrete was designed to make cylindrical- concrete specimens of $100 \mathrm{~mm}$ diameter and $200 \mathrm{~mm}$ height with three categories of cement water $(\mathrm{w} / \mathrm{c})$ ratios of $0.53,0.38$ and 0.3 , which are expected to achieve normal, medium, and high strength concrete compressive strength. In each of the w/c designs 6 specimens were made. The sand used is from Muntilan, using split around Semarang city with a maximum aggregate size of $19 \mathrm{~mm}$. To improve concrete workability, concrete mixes using w/c of 0.38 and 0.3 added with Viscocrete of $0.5 \%$. Mixes of gunny fibrous concrete designs are shown in Table 1. In this research, the control specimen is unburned. Other specimens are burned with various temperatures as explained below.

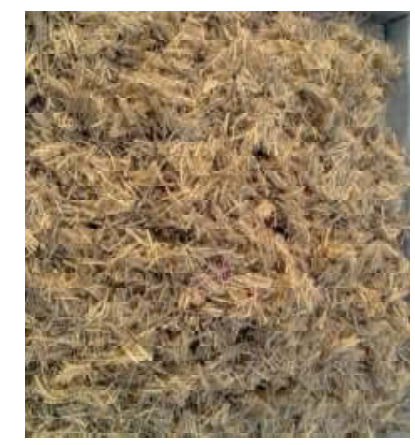

Fig. 1. Gunny fiber

Table 1. Mix Design

\begin{tabular}{lccc}
\hline \multicolumn{1}{c}{ Materials } & $\mathrm{w} / \mathrm{c}=0.53$ & $\mathrm{w} / \mathrm{c}=0.38$ & $\mathrm{w} / \mathrm{c}=0.30$ \\
\hline Cement $\left(\mathrm{kg} / \mathrm{m}^{3}\right)$ & 350 & 20 & 485 \\
\hline Fly Ash $\left(\mathrm{kg} / \mathrm{m}^{3}\right)$ & - & 74 & 83 \\
\hline Water $\left(1 \mathrm{t} / \mathrm{m}^{3}\right)$ & 200 & 160 & 140 \\
\hline Viscocrete $0,5 \%\left(1 \mathrm{t} / \mathrm{m}^{3}\right)$ & - & 6.25 & 9 \\
\hline Fine Aggregate $\left(\mathrm{kg} / \mathrm{m}^{3}\right)$ & 725 & 700 & 660 \\
\hline Coarse Aggregate $\left(\mathrm{kg} / \mathrm{m}^{3}\right)$ & 880 & 1040 & 1080 \\
\hline
\end{tabular}




\subsection{Burning of test specimens}

The burning of the test specimens was carried out in such a way that the temperature target of $300^{\circ} \mathrm{C}, 600^{\circ} \mathrm{C}$, and $900^{\circ} \mathrm{C}$ was obtained. Details of the determination of temperature in the test object referring to the investigation conducted by Antonius et al [13].

\subsection{Data acquisition and testing}

Concrete compressive strength testing refers to ASTM C39-94 [15], where the specimens are monotonically tested using compressive testing machines with a capacity of $1000 \mathrm{kN}$. The data obtained was the maximum load which was then calculated into the amount of voltage. Control specimens and post-burn specimens were tested at 120 days.

\section{Experimental Results and Discussion}

The experimental results are, 28- day concrete compressive strength, slump value, maximum load and maximum -compressive stress at various temperatures are shown in Table 2.

Table 2. Experimental results

\begin{tabular}{|c|c|c|c|c|c|c|c|c|c|c|}
\hline \multirow{3}{*}{$\begin{array}{c}f_{c}^{\prime} \\
28 \text { days }\end{array}$} & \multirow{3}{*}{ Specimen } & \multirow{3}{*}{$\begin{array}{l}\text { Average } \\
\text { slump } \\
(\mathrm{mm})\end{array}$} & \multicolumn{8}{|c|}{ Maximum loads and compressive strength (at 120 days) } \\
\hline & & & \multicolumn{2}{|c|}{ Control } & \multicolumn{2}{|c|}{$\mathrm{T}=300^{\circ} \mathrm{C}$} & \multicolumn{2}{|c|}{$\mathrm{T}=600^{\circ} \mathrm{C}$} & \multicolumn{2}{|c|}{$\mathrm{T}=900^{\circ} \mathrm{C}$} \\
\hline & & & $\begin{array}{l}P_{\max } \\
(\mathrm{kN})\end{array}$ & $f_{c}(\mathrm{MPa})$ & $\begin{array}{l}P_{\max .} \\
(\mathrm{kN})\end{array}$ & $f_{c}(\mathrm{MPa})$ & $\begin{array}{l}P_{\max } . \\
(\mathrm{kN})\end{array}$ & $f_{c}(\mathrm{MPa})$ & $\begin{array}{l}P_{\max } . \\
(\mathrm{kN})\end{array}$ & $f_{c}(\mathrm{MPa})$ \\
\hline \multirow{7}{*}{$\begin{array}{l}31.3 \\
\mathrm{MPa}\end{array}$} & 1 & \multirow{6}{*}{70} & 280 & 33.89 & 190 & 24.20 & 170 & 21.66 & 153 & 19.49 \\
\hline & 2 & & 265 & 32.07 & 182 & 23.18 & 181 & 23.06 & 142 & 18.09 \\
\hline & 3 & & 255 & 30.86 & 175 & 22.29 & 163 & 20.76 & 148 & 18.85 \\
\hline & 4 & & 260 & 31.46 & 188 & 23.95 & 166 & 21.15 & 145 & 18.47 \\
\hline & 5 & & 245 & 29.65 & 192 & 24.46 & 155 & 19.75 & 151 & 19.24 \\
\hline & 6 & & 250 & 30.25 & 192 & 24.46 & 162 & 20.64 & 152 & 19.36 \\
\hline & \multicolumn{2}{|c|}{ Average } & 259.2 & 31.36 & 186.5 & 23.76 & 166.2 & 21.17 & 148.5 & 18.92 \\
\hline \multirow{6}{*}{$52 \mathrm{MPa}$} & 1 & \multirow{6}{*}{60} & 430 & 52.04 & 160 & 20.38 & 170 & 21.66 & 150 & 19.11 \\
\hline & 2 & & 475 & 57.48 & 193 & 24.59 & 182 & 23.18 & 144 & 18.34 \\
\hline & 3 & & 443 & 53.61 & 196 & 24.97 & 176 & 22.42 & 149 & 18.98 \\
\hline & 4 & & 425 & 51.43 & 206 & 26.24 & 177 & 22.55 & 157 & 20.00 \\
\hline & 5 & & 445 & 53.85 & 244 & 31.08 & 184 & 23.44 & 158 & 20.13 \\
\hline & 6 & & 408 & 49.38 & 241 & 30.70 & 181 & 23.06 & 162 & 20.64 \\
\hline \multicolumn{3}{|c|}{ Average } & 437.7 & 52.97 & 206.7 & 26.33 & 178.3 & 22.72 & 153.33 & 19.53 \\
\hline \multirow{7}{*}{$\begin{array}{l}77.7 \\
\mathrm{MPa}\end{array}$} & 1 & \multirow{6}{*}{40} & 650 & 78.66 & 310 & 39.49 & 280 & 35.67 & 220 & 28.03 \\
\hline & 2 & & 595 & 72.01 & 323 & 41.15 & 274 & 34.90 & 224 & 28.54 \\
\hline & 3 & & 640 & 77.45 & 321 & 40.89 & 263 & 33.50 & 213 & 27.13 \\
\hline & 4 & & 635 & 76.85 & 316 & 40.25 & 266 & 33.89 & 206 & 26.24 \\
\hline & 5 & & 650 & 78.66 & 304 & 38.73 & 262 & 33.38 & 210 & 26.75 \\
\hline & 6 & & 695 & 84.11 & 313 & 39.87 & 265 & 33.76 & 205 & 26.11 \\
\hline & \multicolumn{2}{|c|}{ Average } & 644.2 & 77.96 & 314.5 & 40.06 & 268.3 & 34.18 & 213 & 27.13 \\
\hline
\end{tabular}

The results shown in Table 2 revealed that the compressive strength of standard burlap sack concrete obtained at 28 days was normal strength concrete $\left(f^{\prime}=31.3 \mathrm{MPa}\right)$, medium strength 
concrete $\left(f_{c}^{\prime}=52 \mathrm{MPa}\right)$ and high- strength concrete $\left(f_{c}^{\prime}=77.6 \mathrm{MPa}\right)$. Similarly, in the normal concrete crash behavior, the average- slump value of concrete tends to decrease with increasing concrete compressive strength.

\subsection{Mode of failure}

The samples of specimens that show the mode of collapse of gunny fibrous concrete at various temperatures are shown in Fig 2, 3, and 4. In general, we can state that the post-burn specimens have experienced longitudinal compressive collapse. It was reasonable due to the fact that the burned specimens experienced a degradation of strength, as a result when under load of the compressive capacity of the test material, It has actually dropped from its normal compressive capacity.

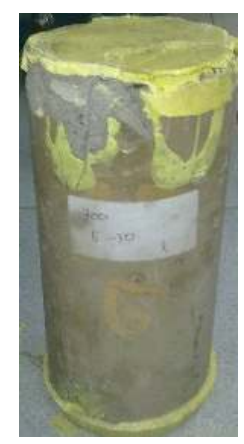

(a) Control specimen

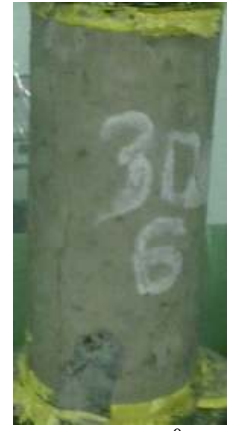

(b) $\mathrm{T}=300^{\circ} \mathrm{C}$

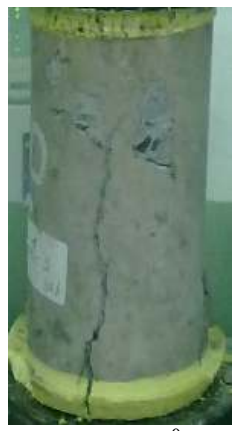

(c) $\mathrm{T}=600^{\circ} \mathrm{C}$

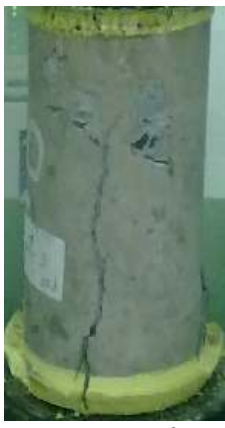

(d) $\mathrm{T}=900^{\circ} \mathrm{C}$

Fig. 2. Failure mode for concrete specimen of $f_{c}^{\prime}=31.3 \mathrm{MPa}$

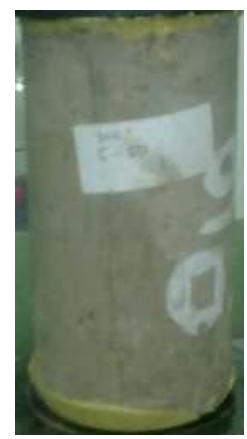

(a) Control specimen

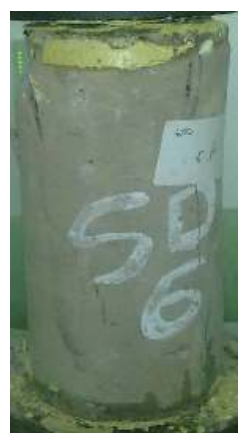

(b) $\mathrm{T}=300^{\circ} \mathrm{C}$

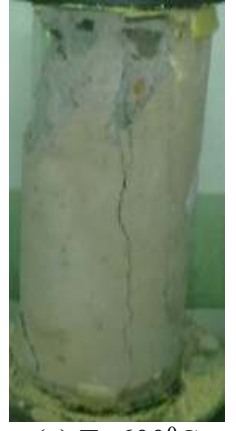

(c) $\mathrm{T}=600^{\circ} \mathrm{C}$

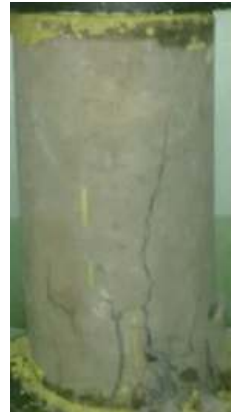

(d) $\mathrm{T}=900^{\circ} \mathrm{C}$

Fig. 3. Failure mode for concrete specimen of $f^{\prime}{ }_{c}=52 \mathrm{MPa}$

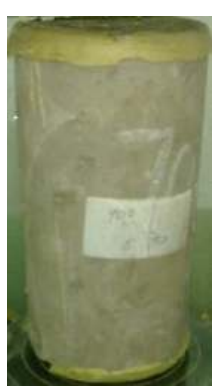

(a) Control specimen

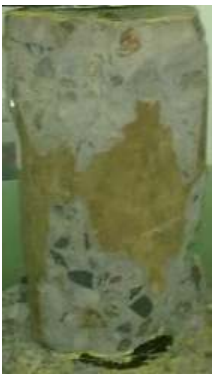

(b) $\mathrm{T}=300^{\circ} \mathrm{C}$

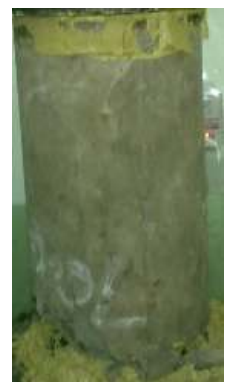

(c) $\mathrm{T}=600^{\circ} \mathrm{C}$

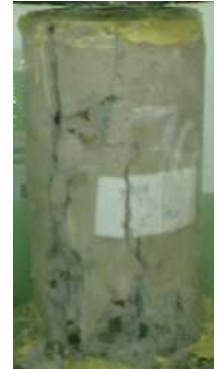

(d) $\mathrm{T}=900^{\circ} \mathrm{C}$

Fig. 4. Failure mode for concrete specimen of $f^{\prime}{ }_{c}=52 \mathrm{MPa}$ 


\subsection{Compressive strength at elevated temperatures}

The relationship of concrete compressive strength to temperature increase in gunny sack fibrous concrete in normal strength concrete $\left(f_{c}^{\prime}=31.3 \mathrm{MPa}\right)$ was shown in Fig. 5. Specimens burned at $300^{\circ} \mathrm{C}$, on the average experienced compressive strength degradation of about $28 \%$ of the compressive strength of its control. If the specimen is burned to a temperature of $600^{\circ} \mathrm{C}$, the compressive strength of concrete decreases by about $35 \%$ from the compressive strength of the control specimen. Furthermore, if the specimen is burned to a temperature of $900^{\circ} \mathrm{C}$, the compressive strength of concrete specimens will be reduced by about $45 \%$ of the compressive strength of the control specimen.

Furthermore, Fig. 6 shows the relationship between the compressive strength of concrete and the temperature for compressive strength of medium concrete $\left(f_{c}^{\prime}=52 \mathrm{MPa}\right)$. Based on these figures and also the data in Table 2, if the specimens are burned at a temperature of $300^{\circ} \mathrm{C}$ then the compressive strength of concrete will loss about $50 \%$ of the compressive strength of the control specimen. The burning of specimens at temperatures of $600^{\circ} \mathrm{C}$ and $900^{\circ} \mathrm{C}$ then each of these specimens will drop by around $55 \%$ and $60 \%$.

The relationship of compressive strength of gunny fibrous concrete to temperature in high strength concrete specimens $\left(f_{c}^{\prime}=77.7 \mathrm{MPa}\right)$ is shown in Fig. 7. Similarly, to the above medium strength concrete, if the specimens are burned at a temperature of $300^{\circ} \mathrm{C}$, the compressive strength of concrete will then also loss around $50 \%$. If the specimens are burned at $600^{\circ} \mathrm{C}$ and $900^{\circ} \mathrm{C}$, the concrete compressive strength will be respectively degraded by about $56 \%$ and $62 \%$, where the value is not much different from the compressive strength degradation of the specimens at 52 MPa compressive strength above.

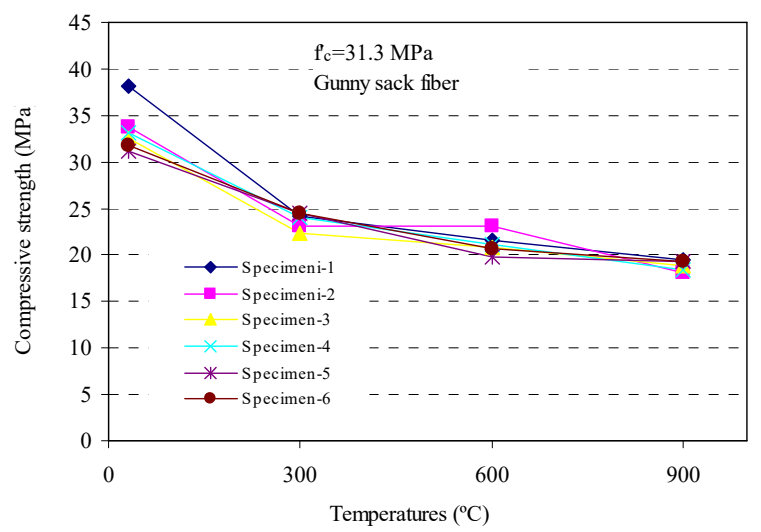

Fig. 5. Compressive strength vs temperatures for $f^{\prime} c=31.3 \mathrm{MPa}$

In addition, an evaluation of the compressive strength of concrete to temperature at variousconcrete compressive strength as shown in Fig. 8. In that figure specimen data of each concrete compressive strength on average (of 6 specimens), and concrete compressive strength was normalized to its own standard compressive strength. It can be seen in Fig. 8 that the degradation of compressive strength of concrete of normal strength and high strength concrete (in this case $f_{c}^{\prime}=52 \mathrm{MPa}$ and $f_{c}^{\prime}=77.7 \mathrm{MPa}$ ) occurs greater/progressive compared with the degradation of normal strength concrete $\left(f_{c}^{\prime}=31.3 \mathrm{MPa}\right)$. 


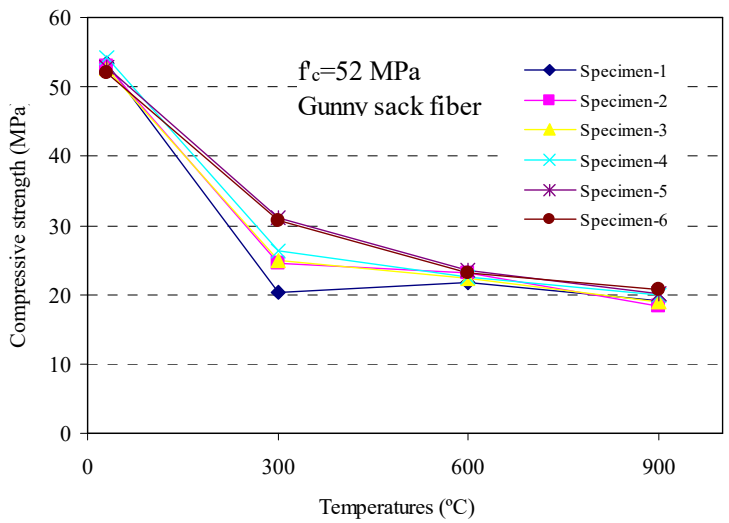

Fig. 6. Compressive strength vs temperatures for $f^{\prime}{ }_{c}=52 \mathrm{MPa}$

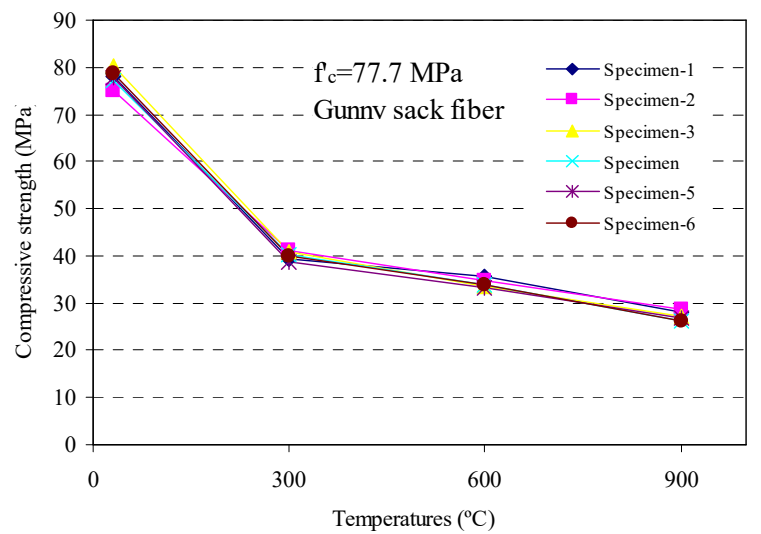

Fig. 7. Compressive strength vs temperatures for $f^{\prime}{ }_{c}=77.7 \mathrm{MPa}$

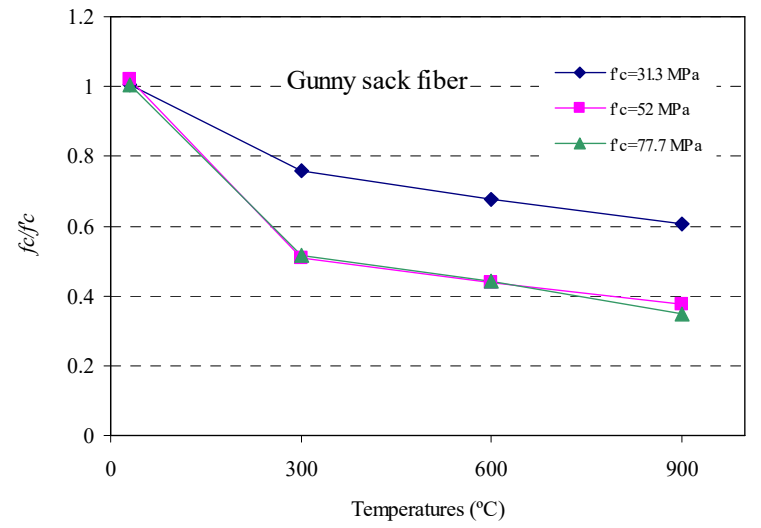

Fig. 8. Normalized of compressive strength vs temperatures with various of $f^{\prime}{ }_{c}$

\subsection{Comparison between gunny sack and steel fiber concrete}

The test results in later studies were compared with the results of compressive strength tests of steel fibrous concrete. Test data used as a comparison were test data by Antonius et al. [10]. Fig. 9 shows that in specimens with $f_{c}^{\prime}=31.3 \mathrm{MPa}$, steel fiber concrete experiences less lose in compressive strength against the degraded compressive strength of gunny fibrous concrete if it is burned at $300^{\circ} \mathrm{C}$. However, in specimens that are burned at temperatures of $600^{\circ} \mathrm{C}$ and $900^{\circ} \mathrm{C}$, steel fibrous concrete specimens lose higher compressive strength when compared to loss in 
compressive strength of gunny fibrous concrete. The same behavior also applies to specimens that have compressive strength of $52 \mathrm{MPa}$ and $77.7 \mathrm{MPa}$ as shown in Fig. 10 and 11. This behavior shows that at temperatures of $600^{\circ} \mathrm{C}$ or more, steel fibrous concrete will experience a more progressive loss of strength compared to gunny sack concrete.

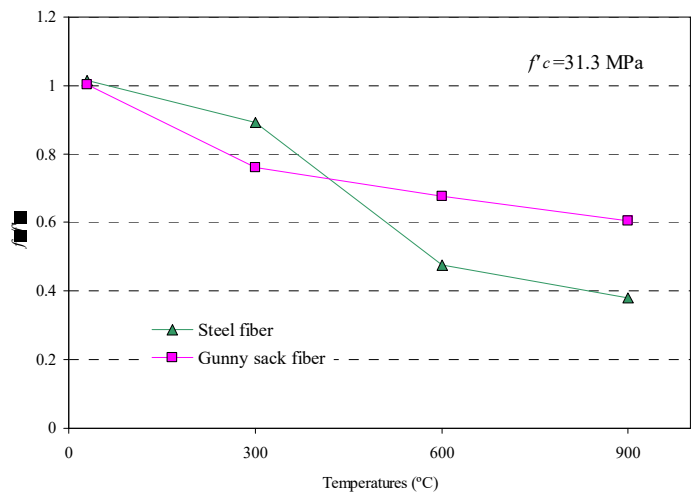

Fig. 9. Comparison of compressive strength degradation between steel fiber with gunny sack fiber concrete for $f^{\prime} c^{\prime}=31.3 \mathrm{MPa}$

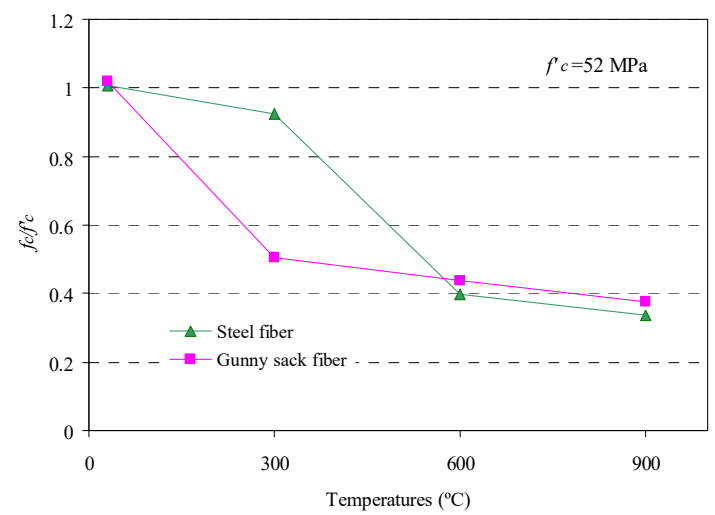

Fig. 10. Comparison of compressive strength degradation between steel fiber with gunny sack fiber concrete for $f_{c}^{\prime}=52 \mathrm{MPa}$

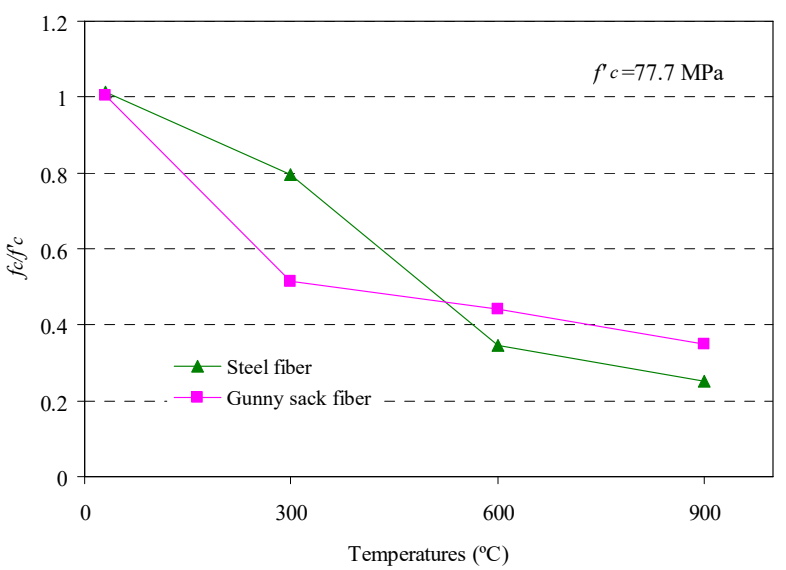

Fig. 11. Comparison of compressive strength degradation between steel fiber with gunny sack fiber concrete for $f^{\prime}{ }^{\prime}=77.7 \mathrm{MPa}$ 


\section{Conclusion}

Based on the results of experiments on compressive strength of gunny fibrous concrete at various temperatures we can conclude several conclusions as follows.

1. Gunny Sack fibrous concrete is producible using a standardized concrete mix design, that enables to produce normal quality, medium quality and high quality gunny fibers.

2. In general, the nature of concrete will lessen along with increasing compressive strength of concrete.

3. Post-burn specimens to high temperatures undergo longitudinal direction collapse mode.

4. The loss of compressive strength of normal strength gunny fiber concrete, either burned at a temperature of $300^{\circ} \mathrm{C}, 600^{\circ} \mathrm{C}$ or $900^{\circ} \mathrm{C}$ it is lower than the compressive strength loss of medium strength and high strength gunny fibers (normal quality and high quality experienced the same compressive strength loss) .

5. Gunny fibrous concrete could lose a greater compressive strength than steel fibrous concrete when burned at a temperature of $300^{\circ} \mathrm{C}$. However, at temperatures of $600^{\circ} \mathrm{C}$ and $900^{\circ} \mathrm{C}$, steel fibrous concrete experiences a progressive loss of compressive strength where the loss of compressive strength is greater in case of the loss in compressive strength of the gunny fibrous concrete.

\section{Acknowledgment}

This research is a part of the research program with advisor of Professor Antonius. The supports received for this research successfully is gratefully acknowledged.

\section{References}

[1] Kodur VKR, Dwaikat MMS, Dwaikat MB. High-temperature properties of concrete for fire resistance modeling of structures, ACI Material Journal, 105(2008), 517-527.

[2] Kodur, V., 2014. Properties of Concrete at Elevated Temperatures. ISRN Civil Engineering, Article ID 478510.

[3] Aslani F, Bastami M. Constitutive relationships for normal- and high-strength concrete at elevated temperatures, ACI Materials Journal, 108(2011), 355-364.

[4] Cement \& Concrete Institute (2010), "Fiber Reinforced Concrete", The Cement \& Concrete Institute, Midrand.

[5] Yet TC, Hamid R, Kasmuri M. Dynamic stress-strain behaviour of steel fiber reinforced high-performance concrete with fly ash, Advances in Civil Engineering, (2012), Article ID 907431.

[6] Janani, S., Santhi, A.S. 2018. Multiple Linear Regression Model for Mechanical Properties and Impact Resistance of Concrete with Fly Ash and Hooked-end Steel Fibers. International Journal of Technology, Volume 9(3), pp. 526-536.

[7] Jansson, A., Lofgren, I., Lundgren, K. and Gyltoft, K., 2012, "Bond of Reinforcement in Self-Compacting Steel-Fibre-Reinforced Concrete", Magazine of Concrete Research, 64, Issue 7, pp. 617-630.

[8] Hadi, M.N.S., 2009, "Reinforcing Concrete Columns with Steel Fibres," Asian Journal of Civil Engineering, 10(1), pp. 79-95.

[9] Shaikh, F.U.A., Taweel, M., 2015. Compressive Strength and Failure Behaviour of Fibre Reinforced Concrete at Elevated Temperatures. Advances in Concrete Construction, Volume 3(4), pp.283-293.

[10] Antonius, A. Widhianto, D. Darmayadi and Gata D. Asfari (2014); Fire Resistance of Normal and High-Strength Concrete with Contains of Steel Fibre; Asian Journal of Civil Engineering, Vol.15(5), October, 655-669.

[11] Purwanto, Antonius and P. Setiyawan (2019); Evaluation on The Mechanical Properties of Steel Fiber-Concrete at Elevated Temperatures, IOP Conference Series: Materials Science and Engineering, Vol. 620, doi:10.1088/1757-899X/620/1/012025. 
[12] Blesak, L., Goremikins, V., Wald, F., Sajdlova, T., 2016. Constitutive Model of Steel Fibre Reinforced Concrete Subjected to High Temperatures. Acta Polytechnica, Volume 56(6), pp.417-424.

[13] Antonius, Purwanto and P. Harprastanti (2019); Experimental Study of the Flexural Strength and Ductility of Post Burned Steel Fiber RC Beams; International Journal of Technology, Vol.10(2), 428-437.

[14] Antonius, H. Indarto and D. Kurniastuti (2012); Mechanical Properties of Gunny Sack Fiber Concrete; Proc. of $1^{\text {st }}$ International Conf. On Sustainable Civil Eng. Structures and Constr. Materials (SCESCM), UGM Yogyakarta, Indonesia, 11-13 Sept, 172-176.

[15] ASTM C 39 - 94 (1996), "Test Method for Compressive Strength of Cylindrical Concrete Spesimens", Annual Books of ASTM Standards, USA, 1996. 